\title{
Применение данных Д33 для целей анализа ландшафтно-экологических систем
}

\author{
Зарубин О.А., аспирант, \\ ФГБОУ ВО «МГУ им. Н.П. Огарёва», \\ 2. Саранск, \\ E-mail: oleg-zarubin@list.ru
}

Научный руководитель: о.2.н., профессор Ямашкин А.А.

На современном этапе развития науки и техники ключевым источником информации, наряду с полевыми и стационарными исследованиями, являются данные, полученные с космо- и аэрофотоснимков. Синтетическая природа, заложенная в данных дистанционного зондирования Земли (ДЗ3), позволяет использовать их для решения практико-ориентированных задач исследования ландшафтно-экологических систем для целей строительства, сельского хозяйства, лесного хозяйства, территориального планирования и т. д.

Любой космический снимок представляет собой зарегистрированное определённым видом сенсоров электромагнитное излучение. К качестве территориального носителя информации выступает пиксель - неделимый наименьший элемент двумерного изображения, характеризующийся яркостью - способностью участка земной поверхности отражать или поглощать свет определенной длины волны.

Однако отдельно взятый канал представляет крайне ограниченную вариацию действий по интерпретации свойств ландшафтно-экологических систем. Специфика применения космофотоснимков заключается в возможности комбинирования каналов, помещая их в красную (R), зеленую (G) и синюю (B) позиции. Таким образом, каждый канал представляет интерес для решения тематических прикладных задач, однако синтетическую информацию о ландшафтно-экологических системах можно получить только в рамках комбинирования каналов при комплексном дешифрировании.

На сегодняшний день существует целый ряд сервисов (спутников и их сенсоров), представляющих космические снимки с разным разрешением, периодичностью, количеством спектральных каналов. Среди наиболее успешных проектов отмечаем данные ДЗ3, получаемые со спутников SPOT, IKONOS, QuickBird, Landsat, TERRA (платформа ASTER).

В качестве ресурса данных ДЗ3 в исследовании нами был выбран комплекс Landsat - старейший проект по получению космофотоснимков. Landsat первой серии был запущен в 1972 году. В настоящее время на орбите Земли действуют спутники Landsat-7 (сенсор ETM+) и Landsat-8 (сенсоры OLI и TIRS), запущенные в 1999 и 2013 годах соответственно. Пространственное разрешение основных каналов соответствует 30 м длины стороны пикселя, что позволяет позиционировать их как снимки высокого разрешения.

В качестве программного продукта для анализа многоканальных снимков выбран ScanEx Image Processor, разработанный группой компаний «СКАНЭКС». К основным достоинствам программного пакета следует отнести:

- наличие необходимого набор средств для обработки спутниковых снимков, в том числе для выполнения таких операций как создание тонально-сбалансированных мозаик, улучшение пространственного разрешения, геометрическая коррекция и 
ортотрансформирование, радиометрическая калибровка, фильтрация изображений, удаление дымки и т. д.;

- возможность работы с векторными слоями в режиме стандартной ГИС, в том числе добавление точечных, линейных и полигональных слоев, оцифровка изображения и т. д.;

- в программе реализованы более 10 алгоритмов классификации изо-бражений на основе автоматизированных и обучаемых методик;

- поддержка большинства современных форматов данных Д33, удобный и интуитивно понятный интерфейс, высокая производительность.

Смена состояний ландшафтно-экологических систем, обусловленное функционированием, динамикой (изменением в рамках единого инварианта) и развитием (сменой инварианта), ставит задачу непрерывного и оперативного их изучения с целью детализации и обновления электронной синтетической ландшафтной карты региональной ГИС и отраслевых карт природных компонентов. Весомое значение здесь имеют анализ и картографирование растительного покрова, водных комплексов, изменений антропогенных и техногенных объектов, сукцессий ландшафта, смен его социально-экономических функций.

Важным направлением в структуре изучения состояний ландшафтноэкологических систем региона с использованием региональной ГИС является проектирование системы тестовых научно-исследовательских полигонов (НИП). Работа с данными ГИС «Мордовия» и использование многозональных космических снимков позволили провести картографирование и анализ ландшафтно-экологических систем региона на базе размещенных в разных типах ландшафтов тестовых НИП, отличающихся хорошей изученностью $[5,6,7]$, различными типами хозяйственного освоения, выполняемыми общественно-экономическими функциями, геоэкологическими ограничениями использования.

Система выделения тестовых НИП основана на сопряженности их расположения в ландшафтной структуре региона. Ландшафты широколиственных лесов и лесостепей эрозионно-денудационных равнин, занимающие водораздельные пространства западных склонов Приволжской возвышенности, характеризующиеся максимальными отметками 280-320 м, представлены полигоном «Чеберчинка». Ландшафты смешанных лесов водно-ледниковых равнин Окско-Донской низменности, занимающие преимущественно западную часть Мордовии, правобережье Мокши и левобережье Алатыря, рассмотрены в рамках реализации методик дешифрирования данных Д33 тестового НИП «Новое Мамангино». Изучение долинных ландшафтов сосредоточено в работе с полигонами «Новое Мамангино» и «Инерка».

В качестве основных этапов использования многозональных снимков в исследовании ландшафтно-экологических систем тестовых НИП выступили: 1) сбор информации о закономерностях природы и хозяйственного освоения территории; 2) выбор и заказ данных Д33; 3) выбор программного обеспечения; 4) предварительная обработка и подготовительный этап работы с данными Д33; 5) тематическая обработка и интерпретация данных Д33; 6) анализ применения полученной информации с целью создания карт для разработки рекомендаций и принятия управленческих решений. Тематическая обработка и интерпретация космических снимков, как узловое звено технологической схемы, представлены комплексом взаимодополняемых визуальных и автоматизированных методов. 
Автоматизированное дешифрирование космических снимков тестовых НИП на базе специализированного программного обеспечения и использования данных НПЦ экологических исследований $[5,6,7]$ позволили апробировать ряд алгоритмов с целью изучения ландшафтно-экологических особенностей территорий. В ходе исследования использовались классификация ISODATA, с помощью древовидного классификатора, нейросетевые методы, вычисление и анализ вегетационных индексов, многоканальное обнаружение изменений, кластерный анализ.

Реализация методик ISODATA и обучаемого древовидного классификатора для целей проектирования карты Land cover НИП «Чеберчинка» позволила в соответствии с программой CORINE выделить классы земной поверхности [4]. Наиболее устойчивы к распознаванию оказались классы водных объектов, пашни и хвойных лесов. Самым трудоемким - выделение классов искусственных поверхностей. Результаты исследования территории со сложным сочетанием природных и антропогенных ландшафтов показал качественное преимущество классификации с обучением методом древовидных классификаторов в силу возможности предварительно определять эталонные образы выделяемых классов.

Апробация нейросетевых методов выполнена в ходе исследования геокомплексов полигона «Новое Мамангино» [3]. Результаты инструментальных исследований позволили определить количество и состав слоев нейронной сети прямого распределения с целью картографирования ландшафтно-экологических систем. Из двух сочетаний каналов, ориентированных на изучение физиономичных дешифровочных признаков, обобщенный лучший результат показала комбинация 6-5-4. На основе полученных результатов разработана модель оптимальной архитектуры нейронной сети с одним «скрытым слоем». Расчетная модель подбора количества нейронов в нем с использованием геометрического правила пирамиды не всегда дает наилучший результат, однако может служить ориентиром для эмпирического подбора, т. к. размер слоя, сильно отличающийся от формализованного, дает значительные ошибки классификации или переобученность сети.

Применение нейронной сети прямого распределения позволило детектировать сложные границы урочищ в морфологической структуре ландшафтов. Так, например, однозначно по космическому снимку интерпретированы крутые склоны, сложенные песками в составе местности надпойменных террас, балки сырые и балки заболоченные в природных территориальных комплексах овражно-лощинно-балочной сети; котловины (древне-озерные), сложенные делювиальными, древне-озерными и торфяными отложениями и другие. По характеру увлажнения и растительным формациям уверенно детектируется граница между местностью пойм и местностью надпойменной террасы.

Анализ состояния растительности ландшафтно-экологических систем с помощью расчета вегетационных индексов реализован на примере НИП «Озеро Инерка» [1]. Приведенные методики позволили на базе ландшафтной карты полигона, разработанной НПЦ экологических исследований [5], выделить геокомплексы с наибольшими и наименьшими показателями биомассы, интенсивности протекания процессов фотосинтеза, биохимического и физиологического стресса. По результатам вычисления индексов NDVI, ARVI, ACL, NDMI, MSAVI2 проведен кластерный анализ, который дал возможность объединить ландшафтно-экологические системы в кластеры с целью изучения динамики состояния фитоценозов. 
Расчет вегетационных индексов за 2013-2016 гг. показал незначительное снижение биомассы фитоценозов всех кластеров, влажностных характеристик и повышение биохимического стресса. По итогам многоканального детектирования изменений по разновременным многозональным снимкам сделан вывод о наиболее и наименее инвариантных геокомплексах.

Таким образом, тактика изучения ландшафтно-экологических систем региона во многом связана с организационными решениями информационного обеспечения. Межотраслевой характер ландшафтно-экологических исследований предъявляет высокие требования к информационному сопровождению - использованию ГИСтехнологий. При этом в основе региональной ГИС должна лежать электронная синтетическая ландшафтная карта, дополняемая в зависимости от целей исследования аналитическими данными [2]. Составление такой карты на основе данных полевых исследований, данных ДЗ3 позволяет в меньшей степени зависеть от характера и точности данных с отраслевых карт.

Синтез знаний на базе региональной ГИС, основан на непрерывном обновлении и уточнении информации с использованием данных ДЗ3. Ценным источником синтетической информации о ландшафтно-экологических системах являются многозональные снимки высокого разрешения, представленные множеством монохромных пиксельных изображений в различных спектральных диапазонах. Технологическая процедура визуального и автоматизированного дешифрирования космоснимков позволяет раскрывать и детализировать информацию о состоянии ландшафтно-экологических систем с целью принятия верных управленческих решений по созданию оптимальной ландшафтно-экологической организации территории.

\section{Список литературы:}

1. Зарубин О.А. К вопросу о применении данных дистанционного зондирования Земли для оценки состояния растительного покрова / О.А. Зарубин, И.В. Жаткина, А.В. Копинов // Научные исследования современных ученых: материалы XV Международной научно-практической конференции. - М.: Изд-во «Олимп», 2016. - С. 322-332.

2. Зарубин О.А. К вопросу об использовании синтетической и аналитической ландшафтных карт в изучении ландшафтно-экологических систем // XLIV Огарёвские чтения: материалы науч. конф.: в 3 ч. Ч 2: Естественные науки. - Саранск: Мордов гос. ун-т, 2016. - С. 228-233.

3. Зарубин О.А. Применение нейронных сетей для целей анализа данных дистанционного зондирования Земли [Электронный ресурс] // Современные научные исследования и инновации. - 2016. - № 8 - Режим доступа: http://web.snauka.ru/issues/2016/08/70887.

4. Зарубин О.А. Технологический процесс проектирования карт Land cover на базе многозональных космических снимков [Электронный ресурс] // Современные научные исследования и инновации. - 2016. - № 9. - Режим доступа: http://web.snauka.ru/issues/2016/09/71253.

5. Культурный ландшафт Мордовии (геоэкологические проблемы и ландшафтное планирование) / [А.А. Ямашкин, И.Е. Тимашев, В.Б. Махаев и др.]; науч. ред. А.А. Ямашкин. - Саранск : Изд-во Мордов. ун-та, 2003. - 204 с. 
6. Ямашкин А.А. Геоэкологический анализ процесса хозяйственного освоения ландшафтов Мордовии / А. А. Ямашкин. - Саранск : Изд-во Мордов. ун-та, 2001. 232c.

7. Ямашкин А.А., Кирюшин А.В., Коваленко А.К. и др. Геоэкологический анализ состояния природно-социально-производственных систем. Саранск: Изд-во Мордов. ун-та, 2004. 260 с.

\title{
Выбор жидкости при проведении гидравлического разрыва пласта
}

\author{
Кокарев М.О., магистр, \\ E-mail: 13050465@mail.ru \\ Семенович С.П., студент, \\ E-mail: 13050465@mail.ru
}

Южно-Российский государственный политехнический университет

(НПИ) имени М.И. Платова, г. Новочеркасск

Научный руководитель: к.т.н., доцент Рыбальченко Ю.М.

На современном этапе развития разработки нефтяных месторождений так называемой «легкой» нефти практически нет. Все месторождения, которые сейчас разрабатываются, либо на стадии завершающейся, либо это новые месторождения, где нефть извлечь трудно. В наших геологических условиях, когда больше 70 \% нефти находится в трудно извлекаемых пластах, ГРП это единственный способ, применяя который становится возможным экономически рентабельно бурить и вводить в эксплуатацию новые скважины и ремонтировать старые.

ГРП является сложным технологическим процессом, вособенности при его проведении в сложных геологических условиях в горизонтально направленных скважинах. В таких ситуациях важным при проведения гидроразрыва пласта является использование высококачественных материалов для приготовления рабочей жидкости. Технология ГРП предусматривает приготовление жидкости разрыва путем смешивания основной фазы (воды или нефти), расклинивающего агента (естественные пески и искусственные керамические или бокситовые проппанты) и специальных химических добавок (стабилизатор глин, загуститель, реагент для снижения показателя фильтрации и трения и т.д.)[1, 2].

В качестве рабочего реагента при проведении гидроразрыва пласта применяются различные жидкости, обладающие разнообразными физическими параметрами. К данным жидкостям применяются следующие требования [1, 2]:

- рабочие жидкости, нагнетаемые в пласт, не должны уменьшать ни абсолютную, ни фазовую проницаемость породы пласта. Поэтому, при ГРП в нефтяных скважинах могут применяться жидкости как на углеводородной основе, так и на водной основе;

- рабочие жидкости для ГРП не должны содержать посторонних механических примесей и при соприкосновении с пластовыми жидкостями и породой пласта не должны образовывать нерастворимых осадков; 